\title{
Prohibitins control cell proliferation and apoptosis by regulating OPA1-dependent cristae morphogenesis in mitochondria
}

\author{
Carsten Merkwirth, ${ }^{1}$ Sascha Dargazanli, ${ }^{1}$ Takashi Tatsuta, ${ }^{1}$ Stefan Geimer, ${ }^{2}$ Beatrix Löwer, ${ }^{2}$ \\ F. Thomas Wunderlich, ${ }^{1}$ Jürgen-Christoph von Kleist-Retzow, ${ }^{3}$ Ari Waisman, ${ }^{1,4}$ \\ Benedikt Westermann, ${ }^{2}$ and Thomas Langer ${ }^{1,5}$ \\ ${ }^{1}$ Institute for Genetics, Centre for Molecular Medicine (CMMC), and Cologne Excellence Cluster on Cellular Stress \\ Responses in Aging-Associated Diseases (CECAD), University of Cologne, 50674 Cologne, Germany; ${ }^{2}$ Institute for Cell \\ Biology and Electron Microscopy Laboratory, University of Bayreuth, 95440 Bayreuth, Germany; ${ }^{3}$ Institute for Vegetative \\ Physiology and Department of Pediatrics, University of Cologne, 50931 Cologne, Germany
}

Prohibitins comprise an evolutionarily conserved and ubiquitously expressed family of membrane proteins with poorly described functions. Large assemblies of PHB1 and PHB2 subunits are localized in the inner membrane of mitochondria, but various roles in other cellular compartments have also been proposed for both proteins. Here, we used conditional gene targeting of murine $P h b 2$ to define cellular activities of prohibitins. Our experiments restrict the function of prohibitins to mitochondria and identify the processing of the dynamin-like GTPase OPA1, an essential component of the mitochondrial fusion machinery, as the central cellular process controlled by prohibitins. Deletion of Phb2 leads to the selective loss of long isoforms of OPA1. This results in an aberrant cristae morphogenesis and an impaired cellular proliferation and resistance toward apoptosis. Expression of a long OPA1 isoform in PHB2-deficient cells suppresses these defects, identifying impaired OPA1 processing as the primary cellular defect in the absence of prohibitins. Our results therefore assign an essential function for the formation of mitochondrial cristae to prohibitins and suggest a coupling of cell proliferation to mitochondrial morphogenesis.

[Keywords: Prohibitin; OPA1; mitochondrial fusion; mitochondrial cristae; apoptosis]

Supplemental material is available at http://www.genesdev.org.

Received October 16, 2007; revised version accepted December 18, 2007.

Mitochondria are multifunctional, reticulated organelles intimately embedded in cellular physiology (Chan 2006a; McBride et al. 2006). Dynamic morphological alterations of mitochondria allow the adaptation of their activities to cellular demands in time and space (Okamoto and Shaw 2005; Chan 2006b; Hoppins et al. 2007). At least four dynamin-related GTPases mediate the fission and fusion of mitochondrial membranes and determine the shape of the mitochondrial reticulum: mitofusins (MFN1 and MFN2) in the outer and OPA1 in the inner membrane control mitochondrial membrane fusion, while DRP1 triggers fission events. Mutations in MFN2 and OPA1 cause neurodegeneration (Alexander et al. 2000; Delettre et al. 2000; Züchner et al. 2004), illustrating the importance of mitochondrial dynamics for neuronal functions.

Prohibitins comprise an evolutionarily conserved family of membrane proteins whose function is poorly un-

\footnotetext{
${ }^{4}$ Present address: Medical Department, Johannes-Gutenberg-University Mainz, 55131 Mainz, Germany.

${ }^{5}$ Corresponding author.

E-MAIL Thomas.Langer@uni-koeln.de; FAX 49-221-470-6749.

Article is online at http://www.genesdev.org/cgi/doi/10.1101/gad.460708.
}

derstood (Nijtmans et al. 2002; Mishra et al. 2005). Multiple copies of two homologous subunits, PHB1 (BAP32, often simply termed prohibitin) and PHB2 (BAP37, REA), form large complexes in the inner membrane of mitochondria (Ikonen et al. 1995; Coates et al. 1997; Berger and Yaffe 1998). The ring-like shape of yeast prohibitin complexes (Back et al. 2002; Tatsuta et al. 2005) and the sequence similarity to lipid raft-associated proteins of the SPFH family suggest a scaffolding function of prohibitins, which may define membrane microdomains (Tavernarakis et al. 1999; Langhorst et al. 2005; Morrow and Parton 2005; Browman et al. 2007). Such an activity could explain synthetic lethal interactions of prohibitins with a diverse set of genes in yeast (Berger and Yaffe 1998; Birner et al. 2003; Nolden et al. 2005; Osman et al. 2007) as well as multiple cellular roles that have been assigned to prohibitins in mammals.

Inactivation of prohibitin genes in multicellular organisms like mouse and Caenorhabditis elegans revealed essential functions during organismal development (Sanz et al. 2003; Park et al. 2005). However, the molecular basis of these loss-of-function phenotypes is unclear. Most importantly, although a mitochondrial localization 
is widely accepted, PHB1 and PHB2 have also been identified in the nucleus and the plasma membrane in certain mammalian cell lines (Fusaro et al. 2003; Kurtev et al. 2004; Kasashima et al. 2006). Subunits of prohibitins have been suggested to regulate cell cycle and apoptotic processes by interacting with retinoblastoma tumor suppressor protein and p53 (Nuell et al. 1991; Wang et al. 2002; Kasashima et al. 2006), to repress the transcriptional activity of estrogen receptors by interacting with histone deacetylases (Montano et al. 1999; Kurtev et al. 2004), to modulate epithelial cell adhesion and migration by interacting with c-Raf (Rajalingam et al. 2005), or to function as cell surface receptors (Terashima et al. 1994; Mengwasser et al. 2004; Sharma and Quadri 2004). It should be noted, however, that many of these studies did not consider a mitochondrial localization of prohibitins and addressed only the function of either PHB1 or PHB2, although both proteins have been demonstrated to assemble quantitatively with each other (Coates et al. 2001).

Here, we used conditional gene targeting of murine $P h b 2$ and define an essential role of the prohibitin complex for the processing of OPAl within mitochondria that results in impaired cell proliferation, resistance toward apoptosis, and mitochondrial cristae morphogenesis.

\section{Results}

\section{Conditional gene targeting of murine Phb2}

To investigate the function of PHB2 in vivo, we used conditional gene targeting using Cre-lox $P$-mediated recombination. The murine Phb2 gene is located on Chromosome 6 and composed of nine exons (Fig. 1A). We constructed a gene replacement vector that introduced a gene cassette consisting of the neomycin resistance gene $(\mathrm{NeO})$ and a flanking loxP site upstream of exon 3 and a loxP site downstream from exon 4 into the endogenous $P h b 2$ gene (Fig. 1A). Deletion of the lox $P$-flanked exons 3 and 4 by Cre-recombinase causes a frameshift mutation resulting in a stop of translation at amino acid 73 of PHB2. After injection of embryonic stem (ES) cells harboring the targeted allele (Supplemental Fig. S1) germline transmission was confirmed by Southern blot analysis (Fig. 1B). Heterozygous $\mathrm{Phb}^{+/-}$animals were generated upon breeding of $\mathrm{Phb}^{f l l+}$ mice with a Cretransgenic mouse strain allowing universal expression of Cre-recombinase in all tissues (Schwenk et al. 1995). Intercrossings of $\mathrm{Phb2}^{+/-}$mice neither revealed viable $P h b 2^{-/-}$offspring nor were homozygous mutant embryos identified before embryonic day 8.5 (Supplemental Table S1). Similarly, breeding of $P h b 2^{f l l+}$ mice with a Cre line expressing Cre-recombinase specifically in the brain did not produce viable offspring (Supplemental Table S1). These findings are in agreement with previous observations using a conventional knockout strategy (Park et al. 2005) and suggest an essential function of PHB2 in early embryonic development.

To define functional consequences of a deletion of Phb2, mouse embryonic fibroblasts (MEFs) were isolated
A

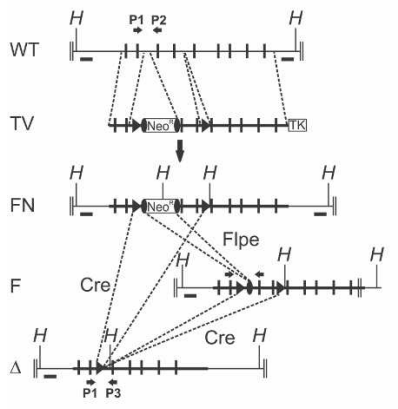

B

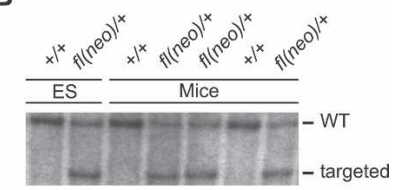

C

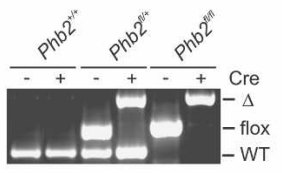

D

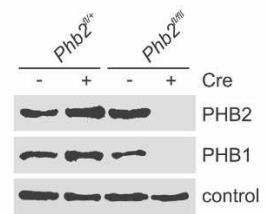

E

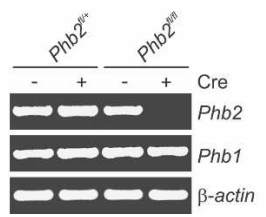

Figure 1. Conditional inactivation of murine $P h b 2$ in vivo and in vitro. (A) Schematic representation of the wild-type $P h b 2$ locus $(\mathrm{WT})$, the targeting vector (TV), the targeted $P h b 2^{f 1(\text { neo }) /+}$ locus after homologous recombination (FN), the conditional $P h b 2^{f l / f 1}$ locus after Flpe-mediated recombination $(\mathrm{F})$, and the knockout locus upon Cre-mediated recombination $(\Delta)$. Positive and negative selection markers $\left(\mathrm{Neo}^{\mathrm{R}}\right.$ and $\left.\mathrm{TK}\right)$, exons (black bars), FRT and $\operatorname{lox} P$ sites (black ovals and black triangles, respectively), external probes (black boxes, A and B), locations of PCR primers (black arrows, P1-P3), and relevant HindIII restriction sites $(\mathrm{H})$ are indicated. $(B)$ Southern blot analysis of germline transmitted offspring harboring the targeted $P h b 2^{f 1(n e o) /+}$ locus. Genomic DNA isolated from ES cells and tail biopsies was digested with HindIII, hybridized, and analyzed by autoradiography. (C) PCR analysis of DNA isolated from MEFs. Amplified DNA fragments for the wild-type (WT), floxed (flox), and knockout $(\Delta)$ locus are shown. $(D)$ Immunoblot analysis of total protein lysates. MEFs, transduced with Cre-recombinase when indicated, were lysed and analyzed by immunoblotting using PHB1- and PHB2-specific antibodies. A cross-reacting band was used as a loading control. (E) RT-PCR analysis of $P h b 1$ and $P h b 2$ transcripts in Phb2-deficient and control MEFs. Transcripts of $\beta$-actin were used as control.

from homozygous $P h b 2^{f 1 / f 1}$ embryos and transduced with purified Cre-recombinase, leading to efficient deletion of Phb2 in vitro (Fig. 1C). Western blot analysis confirmed the absence of PHB2 in Phb2-/- cells (Fig. 1D). Notably, depletion of PHB2 was accompanied by the loss of its assembly partner PHB1 (Fig. 1D). RT-PCR experiments demonstrated that transcription of $P h b 1$ proceeds irrespective of the presence of Phb2 in the cells (Fig. 1E). Thus, similar to other organisms (Berger and Yaffe 1998; Sanz et al. 2003), murine PHB1 and PHB2 are functionally interdependent, defining the assembled prohibitin complex as the functionally active unit.

\section{PHB2 ensures cell proliferation and protects} against apoptosis

The effect of $P h b 2$ deletion on cell proliferation was assessed by determining the ${ }^{3} \mathrm{H}$-thymidine incorporation 
in $P h b 2^{f l /+}$ and $P h b 2^{f l / f 1}$ fibroblasts transduced with Crerecombinase. Whereas Cre-transduction did not affect DNA labeling in heterozygous $P h b 2^{f l /+}$ cells, incorporation of ${ }^{3} \mathrm{H}$-thymidine was strongly impaired in cells lacking PHB2 (Fig. 2A). Consistently, cell growth was impaired in $P h b 2^{f l / f 1}$ cells after Cre-transduction $\left(P h b 2^{-/-}\right)$(Fig. 2B).
A

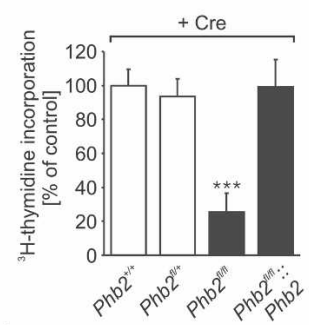

D

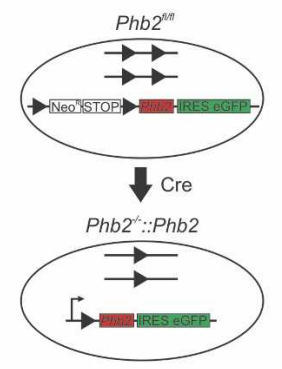

$\mathbf{F}$

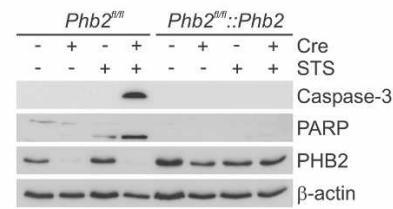

G

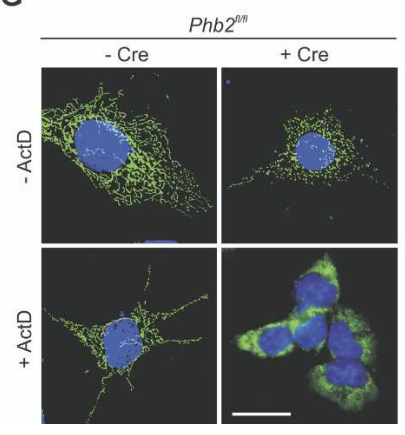

B

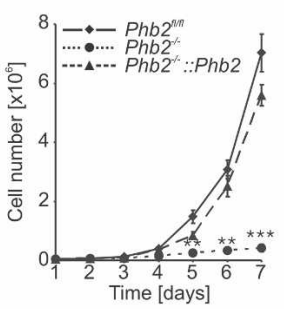

E
C

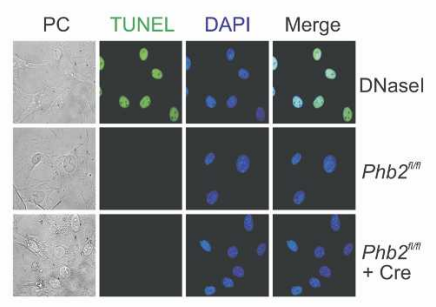

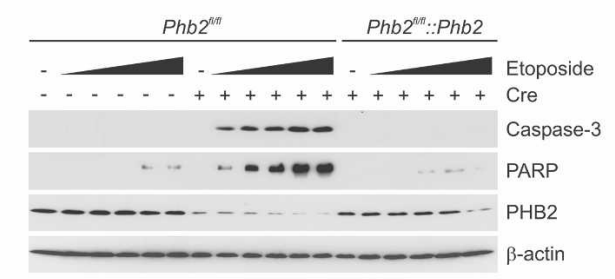

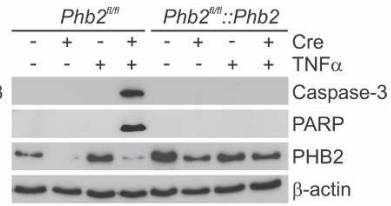

H

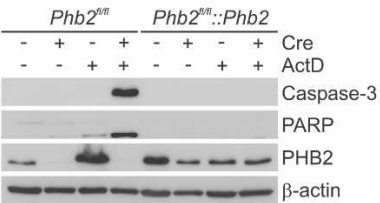

- - - - $\beta$-actin

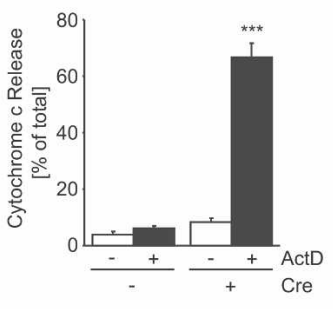

Figure 2. Phb2 is required for cell proliferation and apoptotic resistance. $(A)$ Incorporation of ${ }^{3} \mathrm{H}$-thymidine in MEFs after Cretransduction. Data represent mean \pm standard deviations of three independent experiments. $\left(^{\star \star \star}\right) P<0.001$. $(B)$ Growth curves of PHB2-deficient and control MEFs. Cells $\left(5 \times 10^{4}\right)$ were plated on $60-\mathrm{mm}$ dishes and Cre-transduced when indicated. Triplicates of cell samples were counted per time point. $\left.\left(^{\star \star}\right) P<0.01 ;\left.\right|^{\star \star \star}\right) P<0.001 .(C)$ TUNEL staining of $P h b 2^{f l / f 1}$ MEFs treated with Cre-recombinase when indicated. DNase I-treated MEFs were analyzed in parallel for control. Bar, $10 \mu \mathrm{m} .(D)$ Cre-induced expression of $P h b 2$ in Phb2-deficient MEFs. Phb2 ${ }^{f l / f 1}$ MEFs were stably transfected with the CAGs-NeoR-STOP-IRES-EGFP constructs harboring the Phb2 cDNA $\left(P h b 2^{f l / f 1}:: P h b 2\right)$. Cre-mediated recombination results in the inactivation of the endogenous, floxed $P h b 2$ alleles and, simultaneously, in the removal of the floxed transcriptional STOP cassette, allowing expression of the Phb2 transgene under control of the CAGs promoter. IRES-EGFP expression was used as a reporter. (E) Caspase activation in $P h b 2^{f 1 / f 1}$ and $P h b 2^{f 1 / f 1}:: P h b 2$ cells in the presence of etoposide. Cell lines were transduced with Cre-recombinase when indicated and treated for $5 \mathrm{~h}$ with increasing concentrations of etoposide $(0,0.5,1,5,10,15 \mu \mathrm{M})$. Cell lysates were analyzed by SDS-PAGE and immunoblotting using antibodies directed

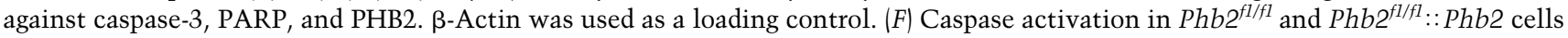
by various intrinsic and extrinsic apoptotic stimuli. After Cre-transduction, cells were treated with staurosporine (STS, $1 \mu \mathrm{M})$, actinomycin D (ActD, $1 \mu \mathrm{g} / \mathrm{mL})$, or TNF- $\alpha(10 \mathrm{ng} / \mathrm{mL})$ for $5 \mathrm{~h}$. Cell lysates were analyzed as in $E$. (G) Cytochrome $c$ release from prohibitin-deficient mitochondria in the presence of actinomycin D. Cells transduced with Cre-recombinase when indicated were cultivated in the presence or absence of actinomycin D $(1 \mu \mathrm{g} / \mathrm{mL})$ for $5 \mathrm{~h}$ and analyzed by immunofluorescence. Nuclear DNA was stained with DAPI. Bar, $10 \mu \mathrm{m}$. $(H)$ Quantification of cytochrome $c$ release from prohibitin-deficient mitochondria. Data represent mean \pm standard deviation of three independent experiments. Approximately 300 cells of each type were analyzed. $\left(^{\star \star \star}\right) P<0.001$. 
TUNEL staining of PHB2-deficient cells, immunoblotting of cell lysates for activated caspase-3, and cytochrome $c$ immunofluorescence did not provide any evidence for spontaneous apoptosis (Fig. 2C-H). Bax and $\mathrm{Bcl} 2$ as well as the anti-apoptotic protein Haxl accumulated at similar levels in wild-type and PHB2-deficient cells (Supplemental Fig. S2). However, $P h b 2^{-/-}$cells exhibited an increased susceptibility toward various intrinsic and extrinsic apoptotic stimuli (Fig. 2E-H; Supplemental Fig. S2). Activated caspase-3 and cleaved PARP accumulated in PHB2-deficient but not in wild-type MEFs treated with various stimuli of the intrinsic pathway of apoptosis, including etoposide, staurosporine, and actinomycin D (Fig. 2E,F). Notably, the absence of PHB2 affected also the extrinsic pathway of apoptosis induced by TNF $\alpha$ (Fig. 2F). In agreement with these findings, cytochrome $c$ was released from mitochondria of PHB2deficient but not $P h b 2^{f l / f l}$ cells after stimulation with limited concentrations of actinomycin D (Fig. 2G,H).

We established stable $P h b 2^{f l / f l}$ cell lines that harbor PHB2 downstream from a stop-cassette with flanking loxP sites (Fig. 2D). Expression of transgenes can be induced by Cre-transduction of these cells, which results concomitantly in the deletion of genomic Phb2. Expression of PHB2 in $\mathrm{Phb2}^{-/-}$cells restored cell proliferation (Fig. 2A), cell growth (Fig. 2B), and the apoptotic resistance of the cells (Fig. 2E-H), demonstrating that both phenotypes can be solely attributed to the loss of PHB2. We therefore conclude that deletion of murine Phb2 impairs cell proliferation without inducing apoptosis but renders MEFs highly susceptible to apoptotic stimuli.

\section{Cell proliferation depends on mitochondrial targeting of PHB2}

Given the pleiotropic functions that have been suggested for prohibitins in different cellular compartments, we examined whether cellular defects of $\mathrm{Phb2}^{-/-}$cells are caused by the loss of PHB2 within mitochondria. We first replaced conserved arginine residues in the N-terminal mitochondrial targeting sequence of PHB2 (Fig. 3A; Kasashima et al. 2006) and analyzed mitochondrial targeting of the PHB2 variants both in vitro and in vivo. ${ }^{35}$ S-labeled wild-type PHB2 was imported into mitochondria isolated from murine liver and accumulated in a protease-protected form (Fig. 3B). Import of PHB2 depends on a membrane potential across the inner membrane and is not accompanied by proteolytic cleavage (Fig. 3B). Replacement of single positively charged amino acids at position 11,17 , or 24 by alanine did not affect import of PHB2 in vitro; however, it was severely impaired upon mutation of two arginine residues at positions 11 and 17 (PHB2 ${ }^{\text {AARR }}$ ) (Fig. 3C). Similarly, import of a quadruple mutant containing two additional mutations of arginine residues at positions 48 and 54 was blocked in vitro (PHB2 ${ }^{\mathrm{AAAA}}$ ) (Fig. $\left.3 \mathrm{C}\right)$. When transiently expressed as an EGFP fusion protein in MEFs, mitochondrial targeting of PHB2 ${ }^{\mathrm{AARR}}$ was still observed, most likely as a consequence of overexpression of the mutant variant (Fig. 3D). Similarly, PHB2 ${ }^{\text {RRAA }}$-EGFP targeted mitochondria when transiently expressed in MEFs (Fig. $3 \mathrm{D})$. In contrast, PHB2 ${ }^{\mathrm{AAAA}}$-EGFP accumulated in the cytosol, demonstrating that mitochondrial sorting is inhibited in vivo (Fig. 3D).

To examine the activity of the PHB2 variants, we established stable $P h b 2^{f l / f l}$ cell lines allowing the expression of PHB2 $2^{\mathrm{AARR}}, \mathrm{PHB} 2^{\mathrm{RRAA}}$, and PHB2 ${ }^{\mathrm{AAAA}}$ transgenes upon Cre-mediated recombination (see Fig. 2D). Cell proliferation of PHB2-deficient MEFs was restored by transgenic expression of $\mathrm{PHB} 2^{\mathrm{AARR}}$ or $\mathrm{PHB} 2^{\mathrm{RRAA}}$ (Fig. $3 \mathrm{E}$ ), which accumulated at similar levels as PHB2 in $P h b 2^{f l / f}$ cells (Fig. 3F; data not shown). In contrast, expression of the cytosolic variant $\mathrm{PHB} 2^{\mathrm{AAAA}}$ did not support cell proliferation (Fig. 3E). Although expressed (Fig. 3G), neither mitochondrial PHB1 nor cytosolic PHB2 ${ }^{\mathrm{AAAA}}$ accumulated stably in these cells, indicating degradation of both proteins (Fig. 3F). On the other hand, mutations in a putative nuclear localization signal and a nuclear receptor box motif did not interfere with cell proliferation (Supplemental Fig. S3). These results reveal a striking correlation between mitochondrial targeting and the maintenance of cell proliferation, pointing to a crucial role of PHB2 within mitochondria.

\section{PHB2 is required for maintenance of tubular mitochondria and normal cristae morphology}

To examine the morphology of PHB2-deficient mitochondria, we expressed mitochondria-targeted red fluorescent protein in $P h b 2^{+/+}, P h b 2^{f l /+}, P h b 2^{f l / f l}$, and in a $P h b 2^{f l / f 1}$ cell line complemented with Phb2. Ablation of Phb2 by Cre-transduction had severe effects on mitochondrial morphology and led to fragmentation of mitochondria in $>90 \%$ of $\mathrm{Phb}^{-/-}$cells (Fig. 4A,B). Fragmented mitochondria were not observed in $\mathrm{Phb2}^{+/+}$or $P h b 2^{f l /+}$ cells, excluding deleterious effects of Cre-recombinase on mitochondrial morphology (Fig. 4A,B). Cre-mediated expression of $\mathrm{Phb} 2$ in $\mathrm{Phb2}^{-/-}$cells restored the tubular morphology of mitochondria (Fig. $4 \mathrm{~A}, \mathrm{~B})$.

The ultrastructure of mitochondria in Cre-transduced $P h b 2^{f l /+}, P h b 2^{f l / f l}$, and $P h b 2^{f l / f 1}:: P h b 2$ MEFs was examined by electron microscopy (Fig. 4C,D). The presence of loxP-flanked $P h b 2$ or the deletion of Phb2 in heterozygous $P h b 2^{f l /+}$ cells did not affect the ultrastructure of mitochondria (Fig. 4C, panels a,b). However, a large fraction of mitochondria in $\mathrm{Phb2}^{-/-}$cells harbored defective cristae (Fig. 4C [panels d-g], D). Either lamellar cristae were almost completely lost or balloon-like, vesicular structures were detected within mitochondria (Fig. 4C, panels $\mathrm{d}-\mathrm{g}$ ). This effect was largely reversed upon expression of PHB2 in $\mathrm{Phb}^{-/-}$cells (Fig. 4C [panel c], D).

To obtain high-resolution images of the three-dimensional organization of mitochondria, we analyzed serial ultrathin sections of $P h b 2^{f l / f 1}$ and $P h b 2^{-/-}$cells by transmission electron microscopy (Fig. 4E). Three-dimensional models generated from these images revealed the presence of regular lamellar cristae in $P h b 2^{f 1 / f 1}$ cells (Fig. $4 \mathrm{E})$. In contrast, morphologically distinct vesicular structures were observed to accumulate within mitochondria 
Merkwirth et al.

A

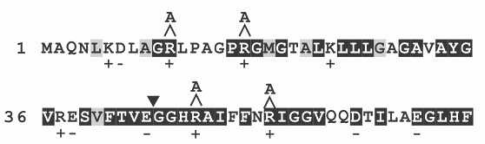

B

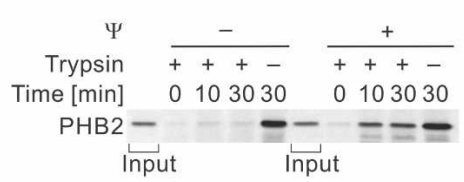

C

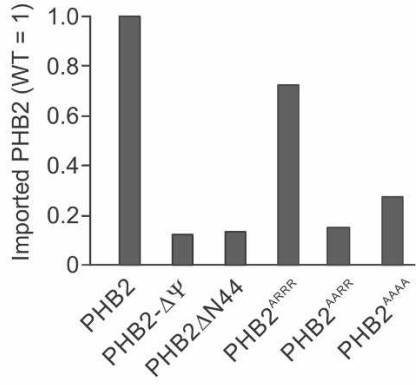

D

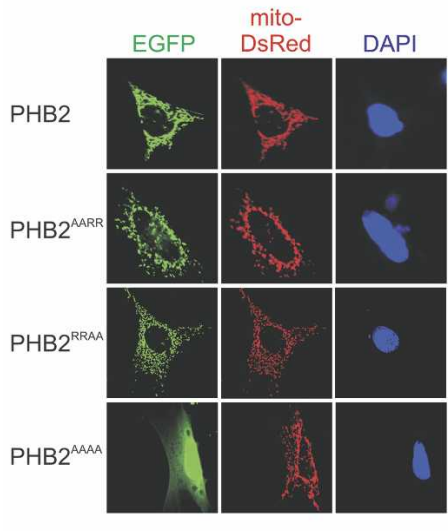

F

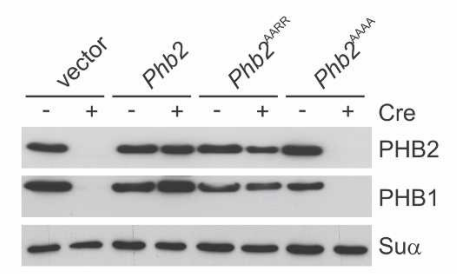

E

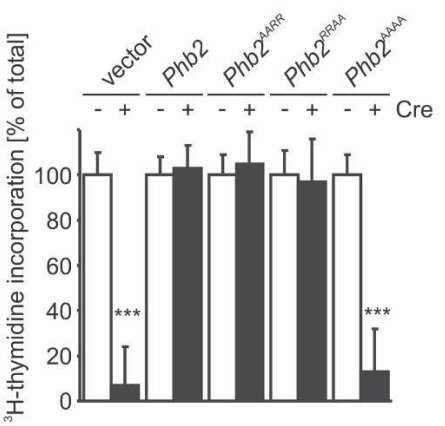

G

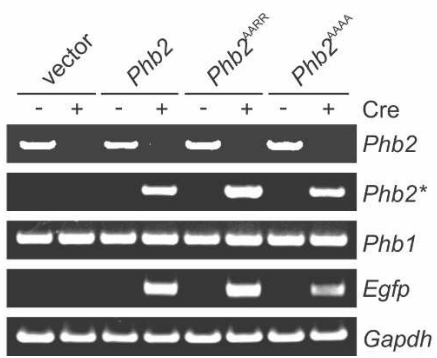

Figure 3. Cell proliferation depends on mitochondrial targeting of PHB2. (A) N-terminal amino acids of murine PHB2. Residues highly conserved among prohibitins are shown in black, and homologous amino acids are shown in gray. Arginine residues replaced by alanine at positions $11,17,48$, and 54 of PHB2 are shown. The $\mathrm{N}$ terminus of PHB2 $\Delta \mathrm{N} 44$ is indicated by an arrowhead. $(B)$ Membrane potential-dependent import of PHB2 into mitochondria. PHB2 was synthesized in a cell-free system in the presence of ${ }^{35} \mathrm{~S}$-methionine and imported for $30 \mathrm{~min}$ at $25^{\circ} \mathrm{C}$ into isolated murine liver mitochondria. The membrane potential across the inner membrane was dissipated by adding valinomycin prior to $(-\Delta \Psi)$ or after completion $(+\Delta \Psi)$ of import. Nonimported preproteins were degraded by trypsin treatment $(50 \mu \mathrm{g} / \mathrm{mL})$. The samples were analyzed by SDS-PAGE and autoradiography. Input corresponds to $10 \%$. (C) Import of PHB2 mutant variants into isolated mitochondria. Import experiments using ${ }^{35} \mathrm{~S}$-labeled PHB2 and mutant variants were performed as described in $B$. Import reactions were quantified by PhosphorImaging analysis. $(D)$ Mitochondrial targeting of PHB2 variants in vivo. MEFs were transfected with EGFP-tagged murine PHB2 and mito-DsRed and analyzed by fluorescence microscopy. PHB2 hybrid proteins carrying mutations at the positions indicated are schematically shown. Bar, $10 \mu \mathrm{m}$. $(E)$ Proliferation of stable cell lines expressing PHB2 variants monitored by ${ }^{3} \mathrm{H}$-thymidine incorporation. Stable cell lines expressing PHB2 mutants (as in $D$ ) and IRES-EGFP were established as described in Figure 2D. Data represent mean values \pm standard deviation of three independent experiments. $(F)$ Immunoblot analysis of MEF cell lines expressing PHB2 or mutant variants thereof. Cell extracts were analyzed by SDSPAGE and immunoblotting using PHB1- and PHB2-specific antibodies. The $\alpha$-subunit of the $\mathrm{F}_{1}$ particle of complex V (Su $\alpha$ ) was used as a loading control. $(G)$ RT-PCR analysis of $P h b 1$ and $P h b 2$ transcripts in various MEF cell lines. Phb2 transcripts derived from the genomic locus $(P h b 2)$ and the transgene $\left(P h b 2^{\star}\right)$ were amplified using allele-specific primer pairs. Transcripts of Gapdh were used as control.

of PHB2-deficient cells (Fig. 4E). We conclude that the formation of lamellar mitochondrial cristae depends on PHB2.

PHB2 controls cleavage of OPA1 in the inner membrane

The dynamin-like GTPase OPA1 is required for both the maintenance of normal cristae in the inner membrane and cristae remodeling during mitochondria-mediated apoptosis (Olichon et al. 2003; Griparic et al. 2004; Frezza et al. 2006). It is therefore conceivable that deletion of $P h b 2$ affects OPA1 function. Expression of eight OPA1 splice variants and proteolytic processing leads to the formation of at least five different isoforms of OPA1, two long forms designated L1 and L2, which can be proteolytically converted to three short forms, designated S3-S5 (Ishihara et al. 2006; Duvezin-Caubet et al. 2007; Griparic et al. 2007; Olichon et al. 2007; Song et al. 2007). Immunoblotting of $P h b 2^{-/-}$and $P h b 2^{-/-}:: P h b 2$ 
A

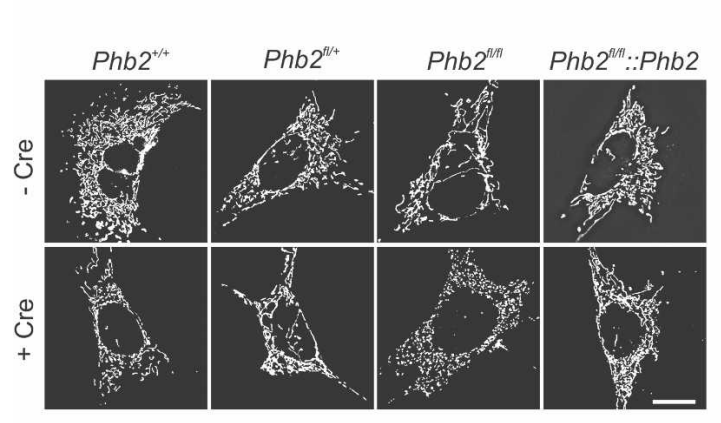

C

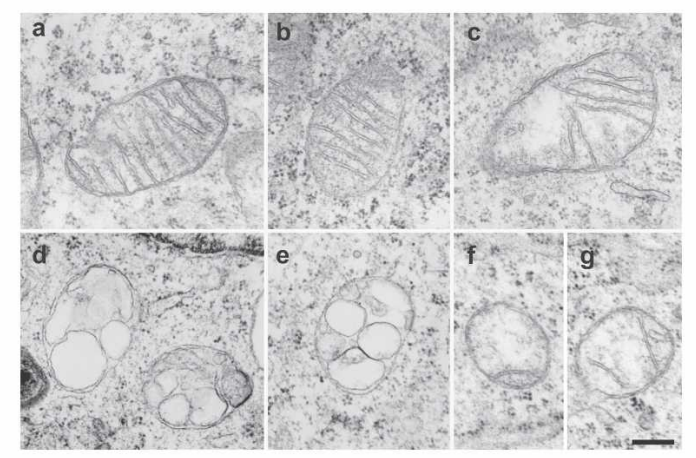

E
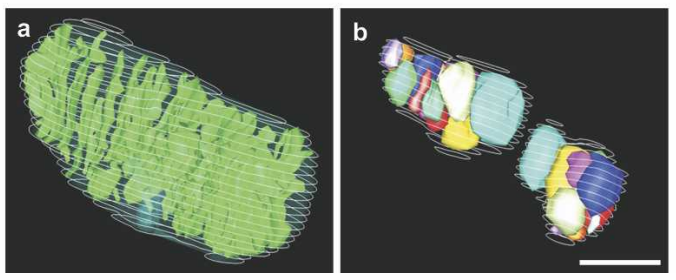

B

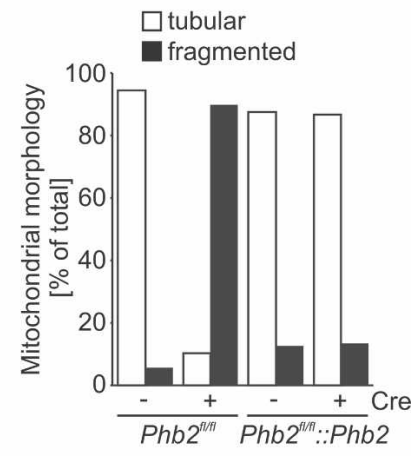

D

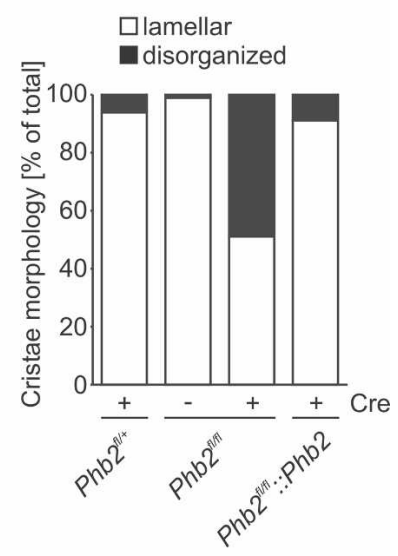

Figure 4. Defective cristae morphogenesis in Phb2 $2^{-/-}$cells. (A) Fragmentation of mitochondria in prohibitin-deficient MEFs. Cell lines were transfected with mito-DsRed, treated with Cre-recombinase when indicated, and analyzed after 72 $\mathrm{h}$ by fluorescence microscopy. Bar, $10 \mu \mathrm{m}$. (B) Quantification of mitochondrial morphology in control $\left(P h b 2^{f 1 / f 1}:: P h b 2\right)$ and prohibitin-deficient MEFs. Cells containing tubular (white bars) or fragmented (black bars) mitochondria were classified. More than 200 cells were scored per experiment. $(C)$ Defective mitochondrial ultrastructure in $\mathrm{Phb2}^{-/-}$cells. Representative transmission electron micrographs of mitochondria in the following cell lines are shown: $P h b 2^{f l / f 1}($ panel $a), P h b 2^{f 1 /+}+$ Cre $($ panel $b), P h b 2^{f 1 / f 1}:: P h b 2+$ Cre (panel $\left.c\right)$, and $P h b 2^{f l / f 1}+$ Cre (panels $d-g$ ). Bar, 500 nm. (D) Quantification of cristae morphology in $P h b 2^{f 1 / f 1}, P h b 2^{f 1 / f 1}:: P h b 2$, and $P h b 2^{f 1 / f 1}$ MEFs transduced with Cre-recombinase when indicated. Approximately $50 \%$ of cells with disorganized cristae morphology contain vesicular cristae structures. Approximately $100 \mathrm{sec}-$ tions of individual cells were scored per experiment. $(E)$ Three-dimensional reconstructions from serial transmission electron microscopy sections of $P h b 2^{f l / f 1}$ cells (panel a) transduced with Cre-recombinase (panel b). Bar, $500 \mathrm{~nm}$.

cells with OPA1-specific antibodies revealed drastic alterations in the pattern of OPA1 isoforms accumulating in the absence of PHB2 (Fig. 5A). While the long forms L1 and L2 and the short form S4 were absent or hardly detectable, S3 and, more pronounced, S5 accumulated in cells lacking PHB2 (Fig. 5A). These alterations were reversed in $\mathrm{Phb2}^{-/-}$cells complemented by PHB2 (Fig. 5A).

Mitochondrial dysfunction and the dissipation of the membrane potential across the inner membrane can induce OPA1 processing and mitochondrial fragmentation (Duvezin-Caubet et al. 2006; Ishihara et al. 2006) and may cause the accumulation of S-OPA1 in the absence of PHB2. We therefore assessed the mitochondrial membrane potential in $\mathrm{Phb2}^{-{ }^{-}}$cells by JC-1 staining and fluorescence-activated cell sorting (Fig. 5B). The membrane potential was maintained in PHB2-deficient cells (Fig. 5B). Moreover, neither cellular ATP levels nor cellular oxygen consumption and the enzymatic activities of respiratory complexes in the inner membrane were af- fected in the absence of PHB2 (Fig. 5C,D; Supplemental Fig. S5). Thus, the accelerated processing of OPA1 in PHB2-deficient cells is not caused by an impaired membrane potential or respiratory activity.

\section{Deficiencies in $\mathrm{Phb2}^{-/-}$cells are caused by the loss} of L-OPA1

The selective loss of L-OPA1 in PHB2-deficient cells may explain both the accumulation of aberrant mitochondria and the increased susceptibility of $\mathrm{Phb}^{-/-}$cells toward apoptotic stimuli. To examine this possibility, we transiently expressed in $P h b 2^{f l / f l}$ cells a Flag-tagged isoform 1 of OPA1 that cannot be cleaved as amino acid residues flanking the processing site had been deleted $\left(\mathrm{L}^{-O P A}{ }^{\Delta}\right)$ (Ishihara et al. 2006). In parallel, a Flag-tagged hybrid protein composed of the short form of OPA1 (amino acids 230-997) fused to the mitochondrial targeting sequence of AIF (amino acids 1-95; S-OPA1) was 
A

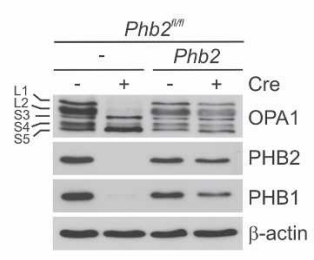

C

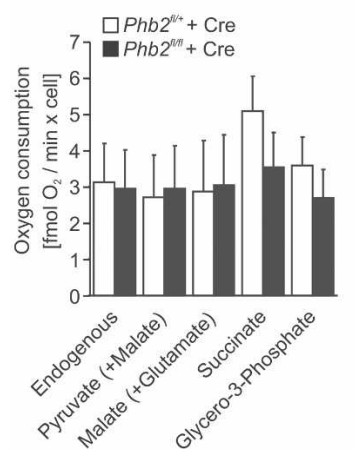

Figure 5. PHB2 controls cleavage of OPA1 but does not affect respiratory activities. (A) Immunoblot analysis of $P h b 2^{f l / f 1}$ and $P h b 2^{f l / f 1}:: P h b 2$ cells transduced with Cre-recombinase. Cell lysates were analyzed by SDS-PAGE and immunoblotting using OPA1-specific, PHB1-specific, PHB2-specific, and, for control, $\beta$-actin-specific antibodies. (B) Maintenance of mitochondrial membrane potential in prohibitin-deficient MEFs. The cell lines indicated were stained with the fluorescent dye JC-1 and analyzed by flow cytometry at $590 \mathrm{~nm}$. Dissipation of the membrane potential with CCCP and unstained cells were used as controls. $(C)$ Oxygen consumption in permeabilized control

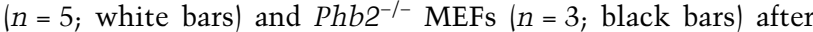
Cre-mediated inactivation of $P h b 2$ under conditions of substrate-driven respiration. Data represent mean value \pm standard deviations. $(D)$ Relative activities of respiratory chain and TCA cycle enzymes in control ( $n=5$, white bars) and $P h b 2^{-1-}$ MEFs ( $n=4$, black bars) after Cre-mediated inactivation of $P h b 2$. (CII) Succinate quinone dichlorophenol indophenol reductase; (CII + CIII) succinate cytochrome $c$ reductase; (CIII) decylubiquinol cytochrome $c$ reductase; (CIV) cytochrome $c$ oxidase; (CS) citrate synthase; (IDH) isocitrate dehydrogenase. Data represent mean value \pm standard deviation.

transiently expressed in $P h b 2^{f 1 / f 1}$ cells (Fig. 6A). Phb2 was deleted by Cre-transduction, and the expression of the OPAl variants was monitored by immunoblot analysis (Fig. 6B). A long isoform of OPA1 was detected in cells upon transfection of $\mathrm{L}-O P A^{\Delta}$ that was absent in PHB2-deficient control cells (Fig. 6B). After coexpression of mitochondria-targeted red fluorescent protein with Land S-OPA1 in $\mathrm{Phb2}^{-/-}$cells, the morphology of mitochondria was assessed by fluorescence microscopy. While $\sim 90 \%$ of PHB2-deficient cells contained fragmented mitochondria, expression of L-OPA ${ }^{\Delta}$ restored tubular mitochondria in $\sim 50 \%$ of the cells (Fig. $6 \mathrm{C}, \mathrm{D}$ ). Expression of S-OPA1, on the other hand, did not signifi- cantly affect the morphology of mitochondria (Fig. 6C,D).

Next, we analyzed the ultrastructure of mitochondria by electron microscopy of $P h b 2^{-/-}$cells that expressed PHB2, S-OPA1, or L-OPA1 ${ }^{\Delta}$. Expression of PHB2 restored normal cristae morphology in $>90 \%$ of $\mathrm{Phb}^{-/-}$ cells (Fig. 6E,F). Strikingly, mitochondrial cristae were also maintained in $\sim 55 \%$ of $\mathrm{Phb}^{-/-}$cells expressing L-OPA $^{\Delta}$ (Fig. 6E,F). In contrast, aberrant mitochondria lacking cristae and containing vesiculated inner membrane structures were formed in $P h b 2^{-/-}$cells regardless of the presence of S-OPA1 in these cells (Fig. 6E,F). We conclude that the long variant of the OPA1 isoform 1 is sufficient to maintain tubular mitochondria and normal cristae in the absence of PHB2. It should be noted that expression of L-OPA1 ${ }^{\Delta}$ appears to substitute for the loss of both L1 and L2 isoforms, indicating functional redundancy. Taken together, the aberrant morphogenesis of mitochondria in PHB2-deficient cells is solely caused by the absence of long OPA1 isoforms.

In further experiments, we examined whether expression of L-OPA $1^{\Delta}$ also restores the apoptotic resistance of $P h b 2^{-/-}$cells. After transient expression of L-OPA1 ${ }^{\Delta}$ or S-OPA1 in Phb2 $2^{f l / f 1}$ cells and deletion of Phb2 by Cretransduction, apoptosis was stimulated by actinomycin D (Fig. 7A). Cells expressing OPA1 variants were identified by cotransfection with mitochondria-targeted DsRed, which enabled us to monitor mitochondrial morphology and cytochrome $c$ release in the same cells. Expression of S-OPA1 did not prevent mitochondrial fragmentation upon Phb2 deletion (see also Fig. 6) nor the release of cytochrome $c$ from PHB2-deficient mitochondria in the presence of actinomycin D (Fig. 7B-D). In contrast, expression of ${\mathrm{L}-\mathrm{OPA} 1^{\Delta}}^{\Delta}$ restored tubular mitochondria and inhibited to a large extent cytochrome $c$ release in the presence of actinomycin D (Fig. 7B-D). Thus, stabilization of L-OPA1 by PHB2 protects cells against apoptosis.

These results identify the control of OPA1 cleavage as the central function of prohibitins within mitochondria. As cell proliferation depends on mitochondria-targeted PHB2, it is conceivable that the proliferation defect of PHB2-deficient cells is a direct consequence of the impaired processing of OPA1 within mitochondria as well. We therefore performed ${ }^{3} \mathrm{H}$-thymidine DNA labeling experiments in $\mathrm{Phb2}^{-/-}$cells transiently expressing S-OPA1 and L-OPA1 ${ }^{\Delta}$ (Fig. 7E). While the presence of S-OPA1 did not improve proliferation of $\mathrm{Phb}^{-/-}$cells, we observed a partial but statistically significant restoration of cell proliferation upon expression of L-OPA1 ${ }^{\Delta}$ (Fig. 7E). These findings indicate that the absence of LOPA1 and defects in mitochondrial morphology deteriorate the proliferation of PHB2-deficient cells.

\section{Discussion}

We used conditional gene targeting of $\mathrm{Phb} 2$ in MEFs to define cellular activities of prohibitins. PHB2 ensures cell proliferation, acts anti-apoptotic, and maintains normal cristae morphology. As PHB1 and PHB2 are func- 
A

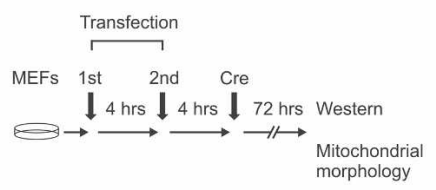

C

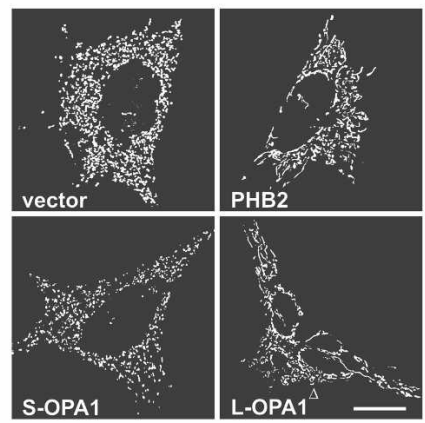

E

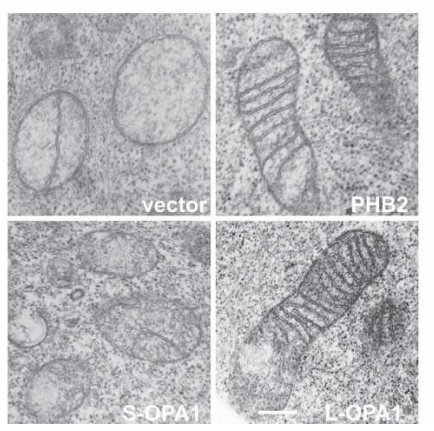

B

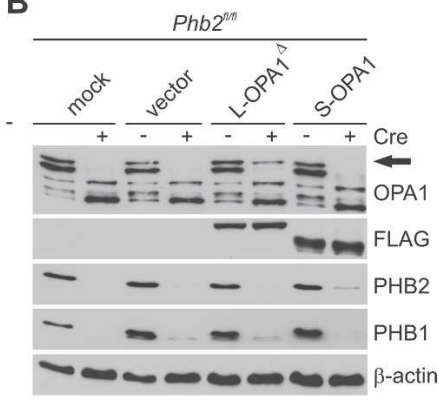

D

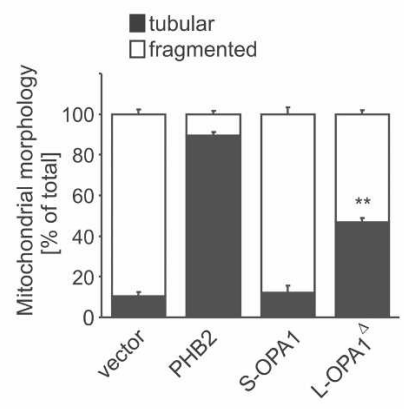

$\mathbf{F}$

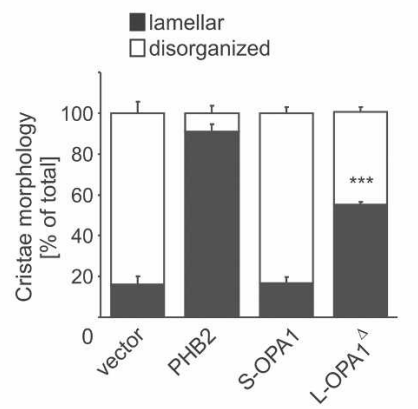

Figure 6. Expression of $\mathrm{L}-\mathrm{OPA} 1^{\Delta}$ restores mitochondrial morphology in $\mathrm{Phb}^{-/-}$cells. (A) Flow chart for complementation experiments using OPA1 variants. MEFs were transiently transfected twice within $4 \mathrm{~h}$ with plasmids indicated and subjected to Cre-transduction. After incubation for a further $72 \mathrm{~h}$, cells were analyzed by immunoblotting and fluorescence microscopy. (B) Immunoblot analysis of $P h b 2^{f l / f 1}$ MEFs transfected with plasmids and transduced with Cre-recombinase as indicated. Endogenous OPA1 isoforms and transfected Flag-tagged OPA1 variants were detected with OPA1and Flag-specific antibodies, respectively. The arrow indicates the presence of the $\mathrm{L}_{\text {-OPA }}{ }^{\Delta}$ in PHB2-depleted MEFs after transfection. $\beta$-Actin was used as a loading control. $(C)$ Restoration of tubular mitochondria in prohibitin-deficient MEFs upon expression of L-OPA1 ${ }^{\Delta}$. $P h b 2^{f l / f 1}$ cells complemented with PHB2 when indicated were transfected with mito-DsRed and the indicated plasmids, treated with Cre-recombinase, and analyzed after $72 \mathrm{~h}$ by fluorescence microscopy. Bar, $10 \mu \mathrm{m}$. $(D)$ Quantification of mitochondrial morphology in prohibitin-deficient MEFs transfected with mito-DsRed and OPAl variants. Cells containing tubular (black bars) or fragmented (white bars) mitochondria were classified. More than 200 cells were scored in three independent experiments. $\left.{ }^{\star \star}\right) P<0.01$. Error bars indicate \pm standard deviations. (E) Restoration of cristae morphology in $\mathrm{Phb2}^{-/-}$cells upon expression of L-OPA1 ${ }^{\Delta}$. MEFs were transfected with the indicated plasmids, and mitochondrial morphology was assessed by transmission electron microscopy. Bar, $500 \mathrm{~nm} .(F)$ Quantification of deficiencies in cristae morphology in $\mathrm{Phb2}^{-/-}$cells upon expression of S-OPAl and L-OPA1 ${ }^{\Delta}$. Approximately 100 sections of individual cells were scored per experiment. $\left(^{\star \star \star}\right) P<0.001$. Error bars indicate standard deviations. tionally interdependent, cellular defects observed in $\mathrm{Phb2}^{-/-}$cells can be attributed to the loss of the assembled prohibitin complex. Complementation assays restrict its function to mitochondria and identify the processing of the dynamin-like GTPase OPA1 in the inner membrane as the central cellular process controlled by prohibitins.

The fragmented mitochondria harboring highly disorganized and swollen cristae in prohibitin-deficient cells strikingly resemble mitochondria that were observed upon down-regulation of OPA1 (Olichon et al. 2003; Griparic et al. 2004). Our experiments in prohibitin-deficient mitochondria ascribe these phenotypes to the selective loss of L-OPA1 isoforms and are therefore consistent with recent findings demonstrating the requirement of both L-OPA1 and S-OPA1 for mitochondrial fusion (Song et al. 2007). Moreover, the absence of L-OPA1 explains the increased susceptibility of $P h b 2^{-/-}$cells to apoptosis. To facilitate cytochrome $c$ release from the intermembrane space, mitochondrial cristae are restructured at early stages of apoptosis, a process controlled by OPA1 (Frezza et al. 2006). A current model suggests that a complex containing L-OPA1 and S-OPA1 controls mitochondrial cristae junctions and prevents the redistribution of cytochrome $c$ from the cristal lumen to the peripheral intermembrane space (Frezza et al. 2006). Accordingly, the loss of L-OPA1 in $\mathrm{Phb2}^{-{ }^{--}}$cells might facilitate cytochrome $c$ release from intracristal compartments. However, alternative models are also conceivable. A recent tomographic analysis of mitochondrial transformation during apoptosis suggests that cristae remodeling is not required for efficient cytochrome $c$ release (Sun et al. 2007). Energized mitochondria containing vesicular intramitochondrial structures have been observed in HeLa cells shortly after induction of apoptosis and cytochrome $c$ release (Sun et al. 2007). This is highly reminiscent of $\mathrm{Phb}^{-/-}$cells, which are fully energized and not apoptotic but more susceptible to apoptotic stimuli. It therefore appears that pre-existing ultrastructural mitochondrial alterations in $\mathrm{Phb2}^{-/-}$cells cause the facilitated progression of the apoptotic program after stimulation, which is required to trigger cytochrome $c$ release. Consistently, expression of L-OPA1 substitutes for the absence of prohibitins and protects 
Merkwirth et al.

A

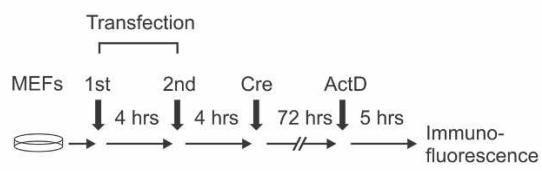

B

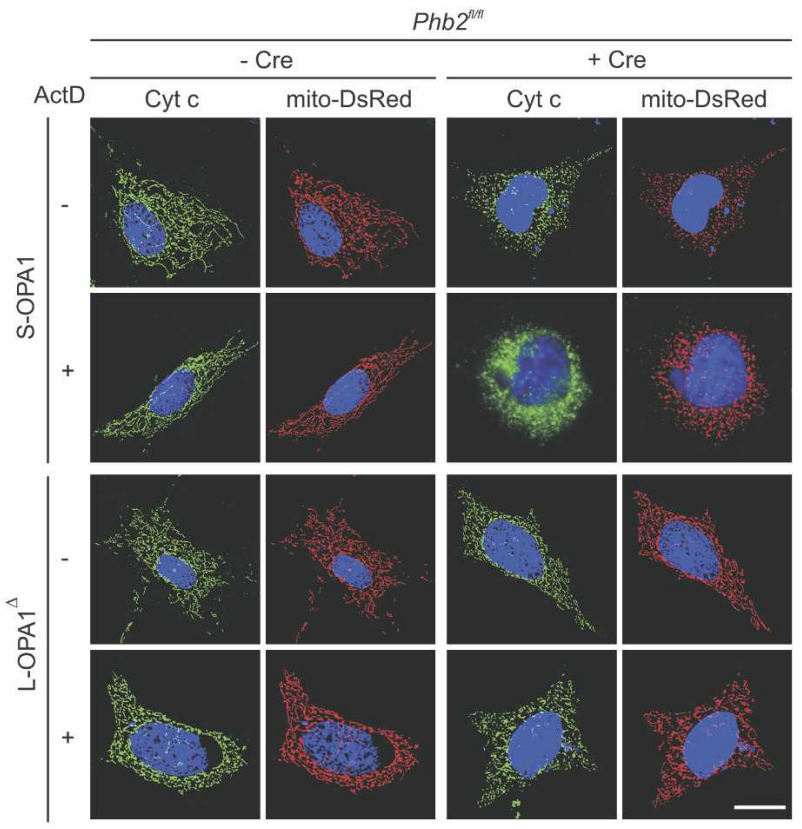

Figure 7. The loss of L-OPAl renders $\mathrm{Phb2}^{-/-}$cells susceptible toward apoptosis. (A) Flow chart for complementation experiments using OPA1 variants. $P h b 2^{-/-}$cells were transiently transfected twice within $4 \mathrm{~h}$ with plasmids indicated and subjected to Cre-transduction. After a further incubation for $72 \mathrm{~h}$, cells were cultivated in the presence of actinomycin $\mathrm{D}(1 \mu \mathrm{g} / \mathrm{mL})$, and induction of apoptosis was assessed monitoring cytochrome $c$ release and caspase activation. $(B)$ Restoration of apoptotic resistance of $P h b 2^{-/-}$cells upon expression of L-OPA1 ${ }^{\Delta}$. After Cre-transduction of $P h b 2^{f 1 / f 1}$ cells and transfection of plasmids encoding S-OPA1 or ${\mathrm{L}-O P A 1^{\Delta}}^{\Delta}$ as indicated, cytochrome $c$ release was monitored by immunofluorescence using cytochrome $c$-specific antibodies. Nuclear DNA was stained with DAPI. Representative images are shown. Bar, $10 \mu \mathrm{m} .(C)$ Quantification of cytochrome $c$ release from prohibitindeficient mitochondria supplemented with S-OPAl or $\mathrm{L}-O P A^{\Delta}$ and stimulated with actinomycin D. Approximately 300 cells were counted for each genotype in three independent experiments. $\left(^{\star \star}\right) P<0.01$. $(D)$ Quantitative assessment of mitochondrial morphology in prohibitin-deficient cells supplemented with S-OPAl or L-OPAl ${ }^{\Delta}$ and stimulated with actinomycin D. Tubular mitochondria in cells transfected with vector (white bars), S-OPA1 (gray bars), or L-OPA1 ${ }^{\Delta}$ (black bars) were classified. Approximately 300 cells were scored for each genotype in three independent experiments. $\left.{ }^{\star \star}\right) P<0.01$. (E) Expression of L-OPA1 ${ }^{\Delta}$ promotes proliferation of $\mathrm{Phb2}^{-{ }^{-}-}$cells. Growth of prohibitin-deficient MEFs was monitored after transfection of S-OPA 1 and L-OPA $1^{\Delta}$ by determining the incorporation of ${ }^{3} \mathrm{H}$-thymidine into DNA. Data represent the mean \pm standard deviation of four independent experiments. $\left(^{\star}\right) P<0.05$ ( $\left.^{\star \star}\right) P<0.01$.

C

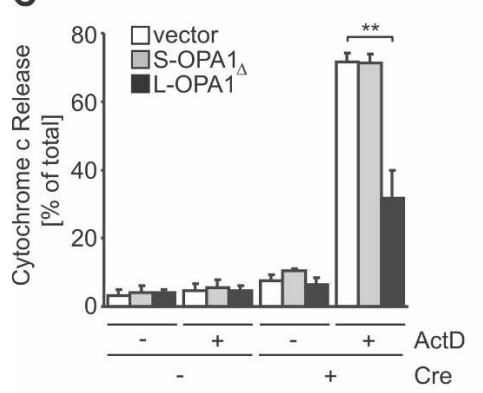

D $\quad$ vector

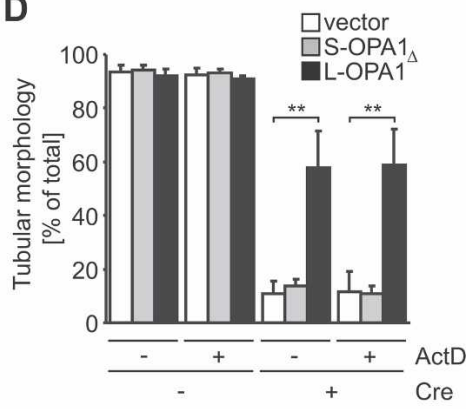

E

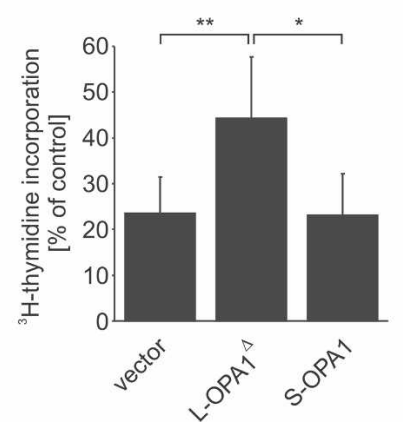

prohibitin-deficient cells against apoptosis, demonstrating that PHB2 exerts its anti-apoptotic function via OPA1. It remains to be established, however, how an altered cristae morphology due to loss of L-OPA1 triggers an increased sensitivity of mitochondria to outer membrane permeabilization. Notably, we did not observe an anti-apoptotic effect of S-OPA1 that has been described previously (Cipolat et al. 2006). This apparent discrepancy could be explained by the absence of L-OPA1 in $\mathrm{Phb2}^{-{ }^{-}-}$cells used in this study, while S-OPA1 was overexpressed in wild-type fibroblasts in previous experiments (Cipolat et al. 2006). It therefore appears likely 
that S-OPA1 exerts its anti-apoptotic effect only in complex with L-OPA1.

Our complementation experiments in $\mathrm{Phb2}^{-/-}$MEFs restrict the function of prohibitins to mitochondria and did not provide any evidence for nonmitochondrial activities. The proliferation of $\mathrm{Phb2}^{-/-}$cells is only restored upon expression of mitochondrially targeted PHB2, assigning a crucial role for cell proliferation to mitochondria-localized prohibitins. Expression of L-OPA ${ }^{\Delta}$ not only restored mitochondrial morphogenesis in $\mathrm{Phb2}^{-/-}$cells and their resistance to apoptosis, but also promoted the proliferation of prohibitin-deficient MEFs. These findings directly link growth deficiencies of $\mathrm{Phb2}^{-/-}$cells to defects in mitochondrial morphogenesis. How an impaired morphology of mitochondria impacts on cell proliferation remains to be determined. Cellular ATP levels and respiration were not grossly affected in the absence of prohibitins, indicating that mitochondria control cell proliferation independent of their function for cellular energy metabolism.

How do prohibitins affect the processing of OPA1 within mitochondria? OPA1 cleavage correlates with the energy status of mitochondria and is induced upon apoptosis (Duvezin-Caubet et al. 2006; Baricault et al. 2007). However, deletion of Phb2 did not affect the mitochondrial membrane potential or respiratory activity, nor do PHB2-deficient cells undergo apoptosis in the absence of stimuli, indicating that OPAl cleavage is under direct control by prohibitins. As deficiencies of $\mathrm{Phb2}^{-{ }^{--}}$cells can be rescued by L-OPA1, a role of prohibitins for the biogenesis or folding of OPA1 appears unlikely. Rather, the loss of L-OPA1 and accumulation of S-OPA1 isoforms in $\mathrm{Phb2}^{-/-}$cells indicates that L-OPAl isoforms are destabilized and processing is facilitated in the absence of PHB2. This is reminiscent of findings in yeast where deletion of prohibitin genes results in an accelerated proteolysis of nonassembled inner membrane proteins by the m-AAA protease (Steglich et al. 1999). Large assemblies of prohibitins and $\mathrm{m}$-AAA proteases are present in the mitochondrial inner membrane (Steglich et al. 1999). Moreover, reconstitution experiments in yeast revealed that various mammalian $m$-AAA protease isoenzymes are able to cleave OPA1 (Duvezin-Caubet et al. 2007). Notably, several peptidases appear to regulate OPA1 cleavage at different sites (Cipolat et al. 2006; Ishihara et al. 2006; Duvezin-Caubet et al. 2007; Griparic et al. 2007; Song et al. 2007). In contrast to other OPA1 isoforms, S4 appears to be generated by the i-AAA protease Yme1L (Griparic et al. 2007; Song et al. 2007). It accumulates at decreased levels absent in $\mathrm{Phb2}^{-/-}$cells, suggesting that prohibitins may regulate the cleavage of OPA1 by various peptidases.

We propose that prohibitins serve as scaffolds in the inner membrane and define the spatial organization of components that control the stability and processing of OPA1 and coordinate membrane fusion. Ring-like prohibitin complexes may sequester OPAl and recruit $m$ AAA proteases to membrane domains involved in the fusion process. Considering the sequence similarity of prohibitins to lipid raft-associated proteins (Tavernara- kis et al. 1999; Langhorst et al. 2005; Morrow and Parton 2005), prohibitins may also promote the lateral segregation of membrane lipids resulting in the formation of lipid microdomains. Surrounding membrane lipids are likely to affect the vectorial membrane dislocation of OPA1 or the proteolytic activity of m-AAA proteases. Moreover, increasing evidence points to an important role of lipids and lipid microdomains in various cellular fusion events (Fratti et al. 2004; Altmann and Westermann 2005; Boukh-Viner et al. 2005; Choi et al. 2006) and apoptotic processes (Choi et al. 2007). The identification of prohibitins as regulators of mitochondrial cristae morphology now paves the way for a detailed understanding of the role of spatial membrane organization for the morphogenesis and function of mitochondria.

\section{Materials and methods}

\section{Generation of conditional Phb2 mice}

A targeting vector for the conditional allele of murine Phb2 was generated by insertion of a $1.4-\mathrm{kb}$ genomic fragment containing exons 3 and 4 between two loxP sites of the pRAPIDflirt vector (A. Bruehl and A. Waisman, unpubl.). An upstream 2.2-kb fragment and a $4.5-\mathrm{kb}$ downstream fragment were used as homology arms. Additionally, the targeting construct contained an FRTflanked PGKneoR cassette and the Herpes Simplex Virus thymidine kinase gene (HSV-TK) for positive and negative selection, respectively. The final construct was linearized by SwaI digestion prior to transfection.

Bruce-4 ES cells (Kontgen et al. 1993) derived from C57BL/6 mice were transfected, cultured, and selected as described previously (Kuhn and Torres 2002). G418- and gancyclovir-resistant ES cell colonies were screened by Southern blotting using external and internal genomic probes (Supplemental Fig. S1).

Chimeric mice were generated by injection of $P h b 2^{f(\text { neo }) /+}$ ES cells into blastocysts from CB20 mice. Matings of male chimeras to $\mathrm{C} 57 \mathrm{BL} / 6$ females resulted in germline transmitted offspring of pure C57BL/6 genetic background.

In vivo deletion of the $F R T$-flanked PGKneoR cassette yielding $P h b 2^{f l /+}$ mice was achieved by crossing male germline transmitted mice with FLPe-deleter mice (Rodriguez et al. 2000). $P h b 2^{f l /+}$ mice were intercrossed to obtain the homozygous $P h b 2^{f l / f 1}$ strain. Heterozygous PHB2-deficient mice were generated by crossing $P h b 2^{f l l+}$ mice to the Cre-Deleter strain (Schwenk et al. 1995). Mice were genotyped by PCR using genomic DNA isolated from tail biopsies. PCR primer sequences are available upon request. Care of all animals was within institutional animal care committee guidelines.

\section{Cloning procedures}

Phb2 was PCR-amplified from C57BL/6 mouse liver cDNA and subcloned. Mutations were introduced using the QuikChange Site-Directed Mutagenesis Kit (Stratagene). For cell-free synthesis of PHB2, Phb2 was cloned into pGEM4 (Promega) allowing expression by SP6-RNA polymerase. Full-length and truncated $P h b 2$ were cloned into pEGFP-N3 (Clontech) to produce C-terminal in-frame fusions with EGFP.

To obtain Cre-inducible expression plasmids allowing the generation of stable cell lines (pCAGs-STOP-IRES-EGFP), we inserted a chicken $\beta$-actin promoter (CAGs) into the PacI site of pSTOP-IRES-EGFP (Sasaki et al. 2006) and subcloned Phb2 and mutant variants. 


\section{Transduction of MEFs with Cre-recombinase}

Recombinant His-TAT-NLS-Cre (HTNC) fusion protein was expressed and purified as described previously (Peitz et al. 2002). HTNC was diluted in DMEM/PBS to a final concentration of 3-5 $\mu \mathrm{M}$, sterile-filtered, and applied to MEFs grown in cell culture dishes. Cells were incubated for $20 \mathrm{~h}$, washed with PBS, and supplemented with growth medium. The efficiency of recombination was assessed by Phb2 allele-specific PCR.

\section{Assessment of cell proliferation}

MEFs $\left(1 \times 10^{6}\right)$ were transduced with Cre-recombinase and collected by trypsinization after $60 \mathrm{~h}$. Onto 96 -well tissue culture plates, $1 \times 10^{4}$ cells were seeded per well and labeled for $12 \mathrm{~h} / 1$ $\mu \mathrm{Ci}$ of ${ }^{3} \mathrm{H}$-thymidine per well). MEFs were harvested and spotted onto glass fiber filters. Incorporated ${ }^{3} \mathrm{H}$-thymidine was determined with a microplate scintillation $\beta$-counter.

\section{Fluorescence microscopy}

For Phb2 localization studies, $1 \times 10^{5}$ MEFs were plated on glass coverslips and transfected with the indicated plasmids using Lipofectamine 2000 (Invitrogen). Forty-eight hours after transfection, cells were fixed in $4 \% p$-formaldehyde and stained with DAPI. Images were acquired using a Zeiss Axioplan microscope and processed with the AxioVision software (Zeiss).

Mitochondrial morphology was examined by transfection of mito-DsRed or pEYFP-mito (Clontech) using GeneJuice transfection reagent (Merck Biosciences). MEFs $\left(2 \times 10^{5}\right)$ were plated on coverslips and transfected twice with the indicated plasmids. Mitochondrial morphology was analyzed using the DeltaVision microscope system. Twenty-five stacks were acquired and subjected to deconvolution.

Cytochrome $c$ release was monitored by immunofluorescence microscopy. MEFs $\left(2 \times 10^{5}\right)$ were grown on coverslips, transfected twice, and transduced with Cre-recombinase. MEFs were treated with actinomycin $\mathrm{D}(1 \mu \mathrm{g} / \mathrm{mL})$ for $5 \mathrm{~h}$ and fixed in $4 \% p$-formaldehyde, followed by permeabilization with $0.15 \%$ Triton X-100 in phosphate-buffered saline (PBS) for $15 \mathrm{~min}$. After incubation for $1 \mathrm{~h}$ in blocking buffer $3 \%$ bovine serum albumine in PBS), cells were treated for $12 \mathrm{~h}$ with $\alpha$-cytochrome $c$ antibody (BD Biosciences). MEFs were washed three times for 5 min each with blocking buffer, incubated for $2 \mathrm{~h}$ with Alexa Fluor $488 \alpha$-mouse secondary antibody (Molecular Probes), and stained with DAPI. After three washing steps for 5 min each with blocking buffer, cells were mounted and images were acquired using a DeltaVision microscope system.

\section{Transmission electron microscopy}

MEFs $\left(2 \times 10^{5}\right)$ were plated on glass coverslips (thickness 0.2 $\mathrm{mm})$, transfected, Cre-transduced, and flat-embedded for transmission electron microscopy as follows: After $72 \mathrm{~h}$, cells were fixed in 0.1 M HEPES/KOH (pH 7.2), $4 \mathrm{mM} \mathrm{CaCl}_{2}$, and $2.5 \%$ glutaraldehyde for $4 \mathrm{~h}$ at room temperature. After three rinses with $0.1 \mathrm{M} \mathrm{HEPES} / \mathrm{KOH}(\mathrm{pH} 7.2), 4 \mathrm{mM} \mathrm{CaCl}_{2}$, cells were postfixed in $1 \%$ osmium tetroxide for $45 \mathrm{~min}$ at $4^{\circ} \mathrm{C}$, rinsed three times in distilled water, and incubated in $1 \%$ uranyl acetate for $1 \mathrm{~h}$ at $4^{\circ} \mathrm{C}$. Dehydration of the samples in a graduated ethanol series, infiltration with Epon, and flat embedding was performed according to standard procedures. Ultrathin sections (40-70 nm) were cut and mounted on pioloform-coated copper grids (Plano). Sections were stained with lead citrate and uranyl acetate and viewed with a Zeiss CEM 902 transmission electron microscope (Carl Zeiss) at $80 \mathrm{kV}$. Micrographs were taken using
EMS EM film (Maco). Three-dimensional reconstructions were prepared from scanned films using IMOD software, version 3.5.5 (Kremer et al. 1996).

\section{Cell death analysis}

For TUNEL staining, $1 \times 10^{5}$ MEFs were grown on glass coverslips in six-well plates, treated with Cre-recombinase when indicated, and cultured for $72 \mathrm{~h}$. Cells were fixed in $4 \% p$-formaldehyde for $10 \mathrm{~min}$ and washed in PBS, and TUNEL staining was performed using the DeadEnd Fluorometric TUNEL system (Promega).

MEFs $\left(2 \times 10^{6}\right)$ were transfected twice, transduced with Crerecombinase, and further cultivated for $72 \mathrm{~h}$. To stimulate the induction of apoptosis, cells were treated with TNF $\alpha(20 \mathrm{ng} / \mathrm{mL}$ and $2.5 \mu \mathrm{g} / \mathrm{mL}$ cycloheximide), etoposide $(10 \mu \mathrm{M})$, actinomycin $\mathrm{D}(1 \mu \mathrm{g} / \mathrm{mL})$, or staurosporine $(1 \mu \mathrm{M})$ for $5 \mathrm{~h}$, and cell lysates were analyzed by immunoblotting.

\section{Acknowledgments}

We thank K. Mihara for OPA1 expression plasmids and Gudrun Zimmer for expert technical assistance. This work was supported by grants of the Deutsche Forschungsgemeinschaft, the European Union (6th Framework Programme), and the GermanIsraeli-Project (DIP grant F.5.1) to T.L.

\section{References}

Alexander, C., Votruba, M., Pesch, U.E., Thiselton, D.L., Mayer, S., Moore, A., Rodriguez, M., Kellner, U., Leo-Kottler, B., Auburger, G., et al. 2000. OPA1, encoding a dynamin-related GTPase, is mutated in autosomal dominant optic atrophy linked to chromosome 3q28. Nat. Genet. 26: 211-215.

Altmann, K. and Westermann, B. 2005. Role of essential genes in mitochondrial morphogenesis in Saccharomyces cerevisiae. Mol. Biol. Cell 16: 5410-5417.

Back, J.W., Sanz, M.A., De Jong, L., De Koning, L.J., Nijtmans, L.G., De Koster, C.G., Grivell, L.A., Van Der Spek, H., and Muijsers, A.O. 2002. A structure for the yeast prohibitin complex: Structure prediction and evidence from chemical crosslinking and mass spectrometry. Protein Sci. 11: 24712478.

Baricault, L., Segui, B., Guegand, L., Olichon, A., Valette, A., Larminat, F., and Lenaers, G. 2007. OPA1 cleavage depends on decreased mitochondrial ATP level and divalent metals. Exp. Cell Res. 313: 3800-3808.

Berger, K.H. and Yaffe, M.P. 1998. Prohibitin family members interact genetically with mitochondrial inheritance components in Saccharomyces cerevisiae. Mol. Cell. Biol. 18: 4043-4052.

Birner, R., Nebauer, R., Schneiter, R., and Daum, G. 2003. Synthetic lethal interaction of the mitochondrial phosphatidylethanolamine biosynthetic machinery with the prohibitin complex of Saccharomyces cerevisiae. Mol. Cell. Biol. 14: 370-383.

Boukh-Viner, T., Guo, T., Alexandrian, A., Cerracchio, A., Gregg, C., Haile, S., Kyskan, R., Milijevic, S., Oren, D., Solomon, J., et al. 2005. Dynamic ergosterol- and ceramide-rich domains in the peroxisomal membrane serve as an organizing platform for peroxisome fusion. J. Cell Biol. 168: 761773.

Browman, D.T., Hoegg, M.B., and Robbins, S.M. 2007. The SPFH domain-containing proteins: More than lipid raft markers. Trends Cell Biol. 17: 394-402. 
Chan, D.C. 2006a. Mitochondria: Dynamic organelles in disease, aging, and development. Cell 125: 1241-1252.

Chan, D.C. 2006b. Mitochondrial fusion and fission in mammals. Annu. Rev. Cell Dev. Biol. 22: 79-99.

Choi, S.Y., Huang, P., Jenkins, G.M., Chan, D.C., Schiller, J., and Frohman, M.A. 2006. A common lipid links Mfn-mediated mitochondrial fusion and SNARE-regulated exocytosis. Nat. Cell Biol. 8: 1255-1262.

Choi, S.Y., Gonzalvez, F., Jenkins, G.M., Slomianny, C., Chretien, D., Arnoult, D., Petit, P.X., and Frohman, M.A. 2007. Cardiolipin deficiency releases cytochrome $c$ from the inner mitochondrial membrane and accelerates stimuli-elicited apoptosis. Cell Death Differ. 14: 597-606.

Cipolat, S., Rudka, T., Hartmann, D., Costa, V., Serneels, L., Craessaerts, K., Metzger, K., Frezza, C., Annaert, W., D'Adamio, L., et al. 2006. Mitochondrial rhomboid PARL regulates cytochrome $c$ release during apoptosis via OPA1dependent cristae remodeling. Cell 126: 163-175.

Coates, P.J., Jamieson, D.J., Smart, K., Prescott, A.R., and Hall, P.A. 1997. The prohibitin family of mitochondrial proteins regulate replicative lifespan. Curr. Biol. 7: 607-610.

Coates, P.J., Nenutil, R., McGregor, A., Picksley, S.M., Crouch, D.H., Hall, P.A., and Wright, E.G. 2001. Mammalian prohibitin proteins respond to mitochondrial stress and decrease during cellular senescence. Exp. Cell Res. 265: 262273.

Delettre, C., Lenaers, G., Griffoin, J.M., Gigarel, N., Lorenzo, C., Belenguer, P., Pelloquin, L., Grosgeorge, J., Turc-Carel, C., Perret, E., et al. 2000. Nuclear gene OPA1, encoding a mitochondrial dynamin-related protein, is mutated in dominant optic atrophy. Nat. Genet. 26: 207-210.

Duvezin-Caubet, S., Jagasia, R., Wagener, J., Hofmann, S., Trifunovic, A., Hansson, A., Chomyn, A., Bauer, M.F., Attardi, G., Larsson, N.G., et al. 2006. Proteolytic processing of OPA1 links mitochondrial dysfunction to alterations in mitochondrial morphology. J. Biol. Chem. 281: 37972-37979.

Duvezin-Caubet, S., Koppen, M., Wagener, J., Zick, M., Israel, L., Bernacchia, A., Jagasia, R., Rugarli, E.I., Imhof, A., Neupert, W., et al. 2007. Processing of OPAl reconstituted in yeast depends on the subunit composition of the m-AAA protease. Mol. Biol. Cell 18: 3582-3590.

Fratti, R.A., Jun, Y., Merz, A.J., Margolis, N., and Wickner, W. 2004. Interdependent assembly of specific regulatory lipids and membrane fusion proteins into the vertex ring domain of docked vacuoles. J. Cell Biol. 167: 1087-1098.

Frezza, C., Cipolat, S., Martins de Brito, O., Micaroni, M., Beznoussenko, G.V., Rudka, T., Bartoli, D., Polishuck, R.S., Danial, N.N., De Strooper, B., et al. 2006. OPA1 controls apoptotic cristae remodeling independently from mitochondrial fusion. Cell 126: 177-189.

Fusaro, G., Dasgupta, P., Rastogi, S., Joshi, B., and Chellappan, S. 2003. Prohibitin induces the transcriptional activity of p53 and is exported from the nucleus upon apoptotic signaling. J. Biol. Chem. 278: 47853-47861.

Griparic, L., van der Wel, N.N., Orozco, I.J., Peters, P.J., and van der Bliek, A.M. 2004. Loss of the intermembrane space protein Mgm1/OPAl induces swelling and localized constrictions along the lengths of mitochondria. J. Biol. Chem. 279: 18792-18798.

Griparic, L., Kanazawa, T., and Van der Bliek, A.M. 2007. Regulation of the mitochondrial dynamin-like protein Opal by proteolytic cleavage. J. Cell Biol. 178: 757-764.

Hoppins, S., Lackner, L., and Nunnari, J. 2007. The machines that divide and fuse mitochondria. Annu. Rev. Biochem. 76: 751-780.

Ikonen, E., Fiedler, K., Parton, R.G., and Simons, K. 1995. Pro- hibitin, an antiproliferative protein, is localized to mitochondria. FEBS Lett. 358: 273-277.

Ishihara, N., Fujita, Y., Oka, T., and Mihara, K. 2006. Regulation of mitochondrial morphology through proteolytic cleavage of OPA1. EMBO J. 25: 2966-2977.

Kasashima, K., Ohta, E., Kagawa, Y., and Endo, H. 2006. Mitochondrial functions and estrogen receptor-dependent nuclear translocation of pleiotropic human prohibitin 2. $J$. Biol. Chem. 281: 36401-36410.

Kontgen, F., Suss, G., Stewart, C., Steinmetz, M., and Bluethmann, H. 1993. Targeted disruption of the MHC class II Aa gene in C57BL/6 mice. Int. Immunol. 5: 957-964.

Kremer, J.R., Mastronarde, D.N., and McIntosh, J.R. 1996. Computer visualization of three-dimensional image data using IMOD. J. Struct. Biol. 116: 71-76.

Kuhn, R. and Torres, R.M. 2002. Cre/loxP recombination system and gene targeting. Methods Mol. Biol. 180: 175-204.

Kurtev, V., Margueron, R., Kroboth, K., Ogris, E., Cavailles, V., and Seiser, C. 2004. Transcriptional regulation by the repressor of estrogen receptor activity via recruitment of histone deacetylases. J. Biol. Chem. 279: 24834-24843.

Langhorst, M.F., Reuter, A., and Stuermer, C.A. 2005. Scaffolding microdomains and beyond: The function of reggie/flottilin proteins. Cell. Mol. Life Sci. 62: 2228-2240.

McBride, H.M., Neuspiel, M., and Wasiak, S. 2006. Mitochondria: More than just a powerhouse. Curr. Biol. 16: 551-560.

Mengwasser, J., Piau, A., Schlag, P., and Sleeman, J.P. 2004. Differential immunization identifies PHB1/PHB2 as bloodborne tumor antigens. Oncogene 23: 7430-7435.

Mishra, S., Murphy, L.C., Nyomba, B.L.G., and Murphy, L.J. 2005. Prohibitin: A potential target for new therapeutics. Trends Mol. Med. 11: 192-197.

Montano, M.M., Ekena, K., Delage-Mourroux, R., Chang, W., Martini, P., and Katzenellenbogen, B.S. 1999. An estrogen receptor-selective coregulator that potentiates the effectiveness of antiestrogens and represses the activity of estrogens. Proc. Natl. Acad. Sci. 96: 6947-6952.

Morrow, I.C. and Parton, R.G. 2005. Flotillins and the PHB domain protein family: Rafts, worms and anaesthetics. Traffic 6: $725-740$.

Nijtmans, L.G.J., Artal Sanz, M., Grivell, L.A., and Coates, P.J. 2002. The mitochondrial PHB complex: Roles in mitochondrial respiratory complex assembly, ageing and degenerative disease. Cell. Mol. Life Sci. 59: 143-155.

Nolden, M., Ehses, S., Koppen, M., Bernacchia, A., Rugarli, E.I., and Langer, T. 2005. The $m$-AAA protease defective in hereditary spastic paraplegia controls ribosome assembly in mitochondria. Cell 123: 277-289.

Nuell, M.J., Stewart, D.A., Walker, L., Friedman, V., Wood, C.M., Owens, G.A., Smith, J.R., Schneider, E.L., Dell'Arco, R., Lumpkin, C.K., et al. 1991. Prohibitin, an evolutionary conserved intracellular protein that blocks DNA synthesis in normal fibroblasts and HeLa cells. Mol. Cell. Biol. 11: $1372-1381$

Okamoto, K. and Shaw, J.M. 2005. Mitochondrial morphology and dynamics in yeast and multicellular eukaryotes. Annu. Rev. Genet. 39: 503-536.

Olichon, A., Baricault, L., Gas, N., Guillou, E., Valette, A., Belenguer, P., and Lenaers, G. 2003. Loss of OPA1 perturbates the mitochondrial inner membrane structure and integrity, leading to cytochrome $c$ release and apoptosis. J. Biol. Chem. 278: 7743-7746.

Olichon, A., Elachouri, G., Baricault, L., Delettre, C., Belenguer, P., and Lenaers, G. 2007. OPA1 alternate splicing uncouples an evolutionary conserved function in mitochondrial fusion from a vertebrate restricted function in apoptosis. Cell 
Death Differ. 14: 682-692.

Osman, C., Wilmes, C., Tatsuta, T., and Langer, T. 2007. Prohibitins interact genetically with Atp23, a novel processing peptidase and chaperone for the $\mathrm{F}_{1} \mathrm{~F}_{0}$-ATP synthase. Mol. Biol. Cell 18: 627-635.

Park, S.-E., Xu, J., Frolova, A., Liao, L., O'Malley, B.W., and Katzenellenbogen, B.S. 2005. Genetic deletion of the repressor of estrogen receptor activity (REA) enhances the response to estrogen in target tissues in vivo. Mol. Cell. Biol. 25: 1989-1999.

Peitz, M., Pfannkuche, K., Rajewsky, K., and Edenhofer, F. 2002. Ability of the hydrophobic FGF and basic TAT peptides to promote cellular uptake of recombinant Cre recombinase: A tool for efficient genetic engineering of mammalian genomes. Proc. Natl. Acad. Sci. 99: 4489-4494.

Rajalingam, K., Wunder, C., Brinkmann, V., Churin, Y., Hekman, M., Sievers, C., Rapp, U.R., and Rudel, T. 2005. Prohibitin is required for Ras-induced Raf-MEK-ERK activation and epithelial cell migration. Nat. Cell Biol. 7: 837-843.

Rodriguez, C.I., Buchholz, F., Galloway, J., Sequerra, R., Kasper, J., Ayala, R., Stewart, A.F., and Dymecki, S.M. 2000. Highefficiency deleter mice show that FLPe is an alternative to Cre-loxP. Nat. Genet. 25: 139-140.

Sanz, M.A., Tsang, W.Y., Willems, E.M., Grivell, L.A., Lemire, B.D., Van der Spek, H., and Nijtmans, L.G.J. 2003. The mitochondrial prohibitin complex is essential for embryonic viability and germline function in Caenorhabditis elegans. J. Biol. Chem. 278: 32091-32099.

Sasaki, Y., Derudder, E., Hobeika, E., Pelanda, R., Reth, M., Rajewsky, K., and Schmidt-Supprian, M. 2006. Canonical NF-кB activity, dispensable for B cell development, replaces BAFF-receptor signals and promotes B cell proliferation upon activation. Immunity 24: 729-739.

Schwenk, F., Baron, U., and Rajewsky, K. 1995. A cre-transgenic mouse strain for the ubiquitous deletion of loxP-flanked gene segments including deletion in germ cells. Nucleic Acids Res. 23: 5080-5081.

Sharma, A. and Quadri, A. 2004. Vi polysaccharide of Salmonella typhi targets the prohibitin family of molecules in intestinal epithelial cells and suppresses early inflammatory responses. Proc. Natl. Acad. Sci. 101: 17492-17497.

Song, Z., Chen, H., Fiket, M., Alexander, C., and Chan, D.C. 2007. OPA1 processing control mitochondrial fusion and is regulated by mRNA splicing, membrane potential, and Yme1L. J. Cell Biol. 178: 749-755.

Steglich, G., Neupert, W., and Langer, T. 1999. Prohibitins regulate membrane protein degradation by the $m$-AAA protease in mitochondria. Mol. Cell. Biol. 19: 3435-3442.

Sun, M.G., Williams, J., Munoz-Pinedo, C., Perkins, G.A., Brown, J.M., Ellisman, M.H., Green, D.R., and Frey, T.G. 2007. Correlated three-dimensional light and electron microscopy reveals transformation of mitochondria during apoptosis. Nat. Cell Biol. 9: 1057-1065.

Tatsuta, T., Model, K., and Langer, T. 2005. Formation of membrane-bound ring complexes by prohibitins in mitochondria. Mol. Biol. Cell 16: 248-259.

Tavernarakis, N., Driscoll, M., and Kyrpides, N.C. 1999. The SPFH domain: Implicated in regulating targeted protein turnover in stomatins and other membrane-associated proteins. Trends Biochem. Sci. 24: 425-427.

Terashima, M., Kim, K.-M., Adachi, T., Nielsen, P.J., Reth, M., Köhler, G., and Lamers, M.C. 1994. The IgM antigen receptor of B lymphocytes is associated with prohibitin and a prohibitin-related protein. EMBO J. 13: 3782-3792.

Wang, S., Fusaro, G., Padmanabhan, J., and Chellappan, S.P. 2002. Prohibitin co-localizes with $\mathrm{Rb}$ in the nucleus and recruits $\mathrm{N}-\mathrm{CoR}$ and HDAC1 for transcriptional repression. Oncogene 21: 8388-8396.

Züchner, S., Mersiyanova, I.V., Muglia, M., Bissar-Tadmouri, N., Rochelle, J., Dadali, E.L., Zappia, M., Nelis, E., Patitucci, A., Senderek, J., et al. 2004. Mutations in the mitochondrial GTPase mitofusin 2 cause Charcot-Marie-Tooth neuropathy type 2A. Nat. Genet. 36: 449-451. 


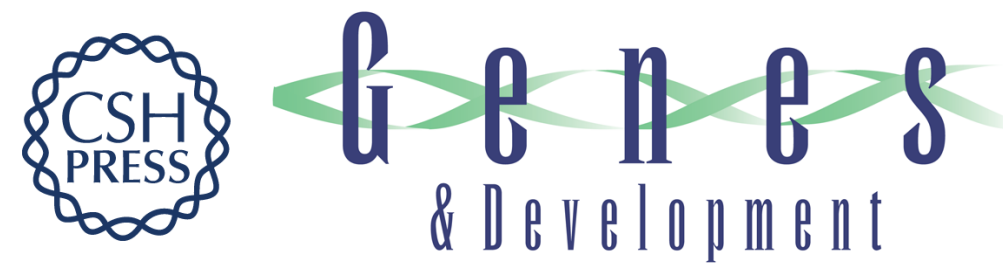

\section{Prohibitins control cell proliferation and apoptosis by regulating OPA1-dependent cristae morphogenesis in mitochondria}

Carsten Merkwirth, Sascha Dargazanli, Takashi Tatsuta, et al.

Genes Dev. 2008, 22:

Access the most recent version at doi:10.1101/gad.460708

Supplemental
Material http://genesdev.cshlp.org/content/suppl/2008/01/29/22.4.476.DC1

References This article cites 60 articles, 23 of which can be accessed free at:

http://genesdev.cshlp.org/content/22/4/476.full.html\#ref-list-1

License

Email Alerting

Receive free email alerts when new articles cite this article - sign up in the box at the top

Service

right corner of the article or click here.

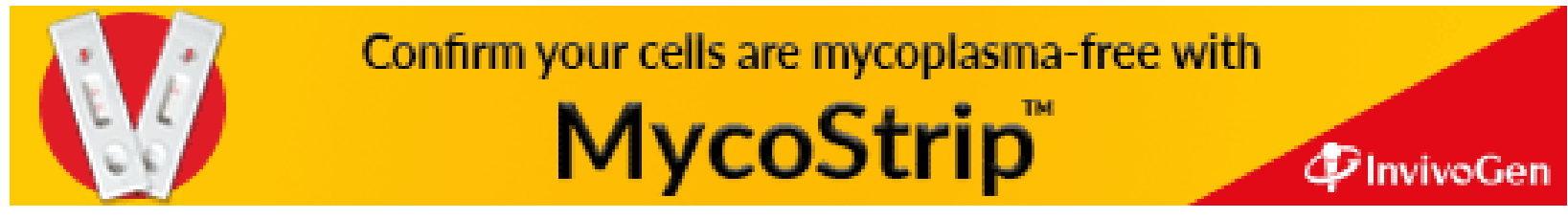

